\title{
Examining religious commitment, personality, and well-being among Latter-Day Saints
}

\author{
Kawika Allen \\ Brigham Young University, gekawika_allen@byu.edu \\ Ofa Hafoka \\ Brigham Young University \\ Lane Fischer \\ Brigham Young University
}

Follow this and additional works at: https://scholarsarchive.byu.edu/facpub

Part of the Other Sociology Commons

\section{Original Publication Citation}

G. E. Kawika Allen, Ofa Hafoka \& Lane Fischer (2019): Examining religious commitment, personality, and well-being among Latter-day Saints, Journal of Religion \& Spirituality in Social Work: Social Thought, DOI: 10.1080/15426432.2019.1617822

\section{BYU ScholarsArchive Citation}

Allen, Kawika; Hafoka, Ofa; and Fischer, Lane, "Examining religious commitment, personality, and wellbeing among Latter-Day Saints" (2019). Faculty Publications. 3171.

https://scholarsarchive.byu.edu/facpub/3171 


\section{Examining religious commitment, personality, and well-being among Latter-day Saints}

\section{G. E. Kawika Allen, Ofa Hafoka \& Lane Fischer}

To cite this article: G. E. Kawika Allen, Ofa Hafoka \& Lane Fischer (2019): Examining religious commitment, personality, and well-being among Latter-day Saints, Journal of Religion \& Spirituality in Social Work: Social Thought, DOI: 10.1080/15426432.2019.1617822

To link to this article: https://doi.org/10.1080/15426432.2019.1617822

曲 Published online: 05 Jun 2019.

Submit your article to this journal $\pi$

View Crossmark data $₫$ 


\title{
Examining religious commitment, personality, and well-being among Latter-day Saints
}

\author{
G. E. Kawika Allen, Ph.D. ${ }^{a}$, Ofa Hafoka, Ph.D. ${ }^{a}$, and Lane Fischer, Ph.D., LPb \\ aDepartment of Counseling Psychology \& Special Education, Brigham Young University, McKay School \\ of Education, Provo, UT; ${ }^{\text {bC} C o u n s e l i n g ~ P s y c h o l o g y ~ \& ~ S p e c i a l ~ E d u c a t i o n, ~ D a v i d ~ O . ~ M c K a y ~ S c h o o l ~ o f ~}$ \\ Education, Brigham Young University
}

\begin{abstract}
This study examined religious commitment, the big five personality traits, social interaction anxiety, and anger among 110 members of The Church of Jesus Christ of Latter-day Saints (LDS). Results suggest the majority of the participants are religious, score high on agreeableness and conscientiousness, and low on social interaction anxiety and anger. Agreeableness mediated the relationship between religious commitment and anger, and extraversion moderated the relationship between religious commitment and social interaction anxiety. Counseling strategies are discussed for social work providers. Implications and future directions are discussed.
\end{abstract}

\section{ARTICLE HISTORY}

Received 17 April 2019

Accepted 8 May 2019

\section{KEYWORDS}

Religiosity; personality; big five; LDS; well-being/

adjustment

Throughout the decades many have attempted to describe transcendent experiences with religiosity and spirituality in relation to well-being. Simply understanding the foundational premises of religious and spiritual living as they relate to subjective well-being can be a complex undertaking. Some of the early writings related to religion and psychology can be linked to Allport and Ross's (1967) two-dimensional model: intrinsic and extrinsic religious motivation. Others have broadly described religiosity and spirituality related to the differences between two basic ways they are manifest. For example, some scholars (McCrae \& Costa, 1999; Roccas, Sagiv, Schwartz, \& Knafo, 2002) described religion as an organized system of beliefs, practices, rituals, and symbols; while others (Cervantes \& Parham, 2005; Walsh, 1999) identified spirituality as traits of a person with transcendent beliefs that are overarching, leading one's life to greater awareness and wholeness (Allen \& Heppner, 2011; Allen \& Wang, 2014). Regardless of how scholars have described religiosity and spirituality, those who identify as religious and/or spiritual have reported a significant psychological impact in their lives.

According to the Gallup survey on Religion in America (2012), 82\% of the population had a religious preference, $77 \%$ belonged to a church or synagogue, $40 \%$ had attended a religious service within seven days prior to the survey, and

CONTACT G. E. Kawika Allen gekawika_allen@byu.edu D Department of Counseling Psychology \& Special Education, Brigham Young University, McKay School of Education, 273 MCKB, Provo, UT 84602 
$55 \%$ ranked religion as very important in their lives. People who prayed and/or meditated regularly reported higher levels of religious satisfaction and happiness, lower levels of depressive symptoms and psychological distress, and a strong social support system that helped them cope with emotional stresses (Allen \& Heppner, 2011; Koenig et al., 1997; Paloma \& Pendelton, 1991; Schneider \& Kastenbaum, 1993; Yeh, Arora, \& Wu, 2006; Yeh, Inman, Kim, \& Okubo, 2006). In addition, much of the research related to religiosity has also examined its associations with personality factors.

\section{Religiousness and personality traits}

Studies (Wink, Ciciolla, Dillon, \& Tracy, 2007; Francis, 2005; Francis \& Ross, 2000; Goldberg \& Saucier, 1998; Kosek, 1999; Piedmont, Ciarrochi, Dy-Liacco, \& Williams, 2009; Saroglou, 2002; Streyffeler \& McNally, 1998) have investigated the association between religiosity and personality. Such investigations have defined personality as "dimensions of individual differences in tendencies to show consistent patterns of thoughts, feelings and actions" (Costa \& McCrae, 1990 , p. 23). Building on these concepts of stable and constant traits, research has been done on the development of categorical traits and dimensions of personality (Costa \& McCrae, 1990; McCrae \& Costa, 1999; Saroglou, 2002). A recent study using Eysenck's three-dimensional model PEN (psychoticism, extraversion, neuroticism) in a variety of cultures and denominations found a relationship between religion and low psychoticism (Saroglou, 2002).

Similarly, studies with the Five-Factor Model (FFM; Cianocchi, Piedmont, \& Williams, 2003; McCrae \& Costa, 1999; Piedmont, 1999, 2005; Streyffeler \& McNally, 1998) have also shown some associations between religiosity and personality traits. Streyffeler and McNally (1998) found that liberal and fundamentalist Protestants showed an inverse association with the openness to experience trait, but not with any other factors of the FFM. Wink, Ciciolla, Dillon, and Tracy (2007) extended these findings by reporting that religiosity positively correlated with agreeableness and conscientiousness; in contrast to who found spiritual seeking to be associated with openness to experience. Some inconsistencies have been found in relationships between religiousness and personality among diverse religious groups. More investigative information is needed among religious people with varying personality traits, particularly relative to psychological well-being and adjustment.

\section{Religiousness and well-being}

Both earlier and more recent studies related to social work practitioners as well as other mental health providers have consistently shown psychological wellbeing to be related to religiousness; similarly, anxiety-induced psychological distress has been found to be lower among religious people with a strong 
spiritual support group (Allen \& Heppner, 2011; Allen \& Wang, ; Derezotes \& Evans, 1995; Hertsgaard \& Light, 1984; Jansen, Motley, \& Hovey, 2010; Maton, 1989). For example, depression among college students has been shown to be lower among those who attended religious services more often (Jansen, Motley, \& Hovey, 2010). During heightened anxiety, religious individuals tended to focus more on and increase their belief in God to buffer the elevated levels (Allen \& Heppner, 2011; Kay, Gaucher, McGregor, \& Nash, 2010).

However, research results on anxiety and religiousness have been inconsistent depending on personal context and level of religiosity. For instance, research on the relationship between prayer and anxiety has had mixed results (Elkins, 1977; Elkins, Anchor, \& Sandler, 1979; Finney \& Malony, 1985): Prayer can be the source of personal and theological conflict, thus increasing levels of anxiety; but prayer and meditation may also reduce levels of anxiety (Elkins, 1977). Research has shown very little association between social anxiety (specifically) and religiosity (Storch, Storch, \& Adams, 2002). Although some research has documented the effects of religious living on psychological adjustment, specifically anxiety, little is known about social anxiety/phobia and social interaction anxiety among religious people.

Some studies have linked heightened anxiety to other emotions. Hong and Withers (1982) found that those who have a tendency to react to stress with high anxiety are more likely to have higher levels of anger. Similarly, studies focused on relationships between negative emotions and personality concluded that extraversion is related to less reactivity in negative emotions (Berenbaum \& Williams, 1995), neuroticism is related to self-reports of negative emotions (Atkinson \& Violato, 1994; Watson \& Clark, 1984), and conscientiousness is related to self-reported anger (Harmon-Jones \& Sigelman, 2001). When dealing with anger in the religious context, some scholars have found that religiosity is inversely correlated with levels of anger (Merrill, Read, \& LeCheminant, 2009).

\section{Purpose of this study}

Although there is empirical information relating religiousness and spirituality to psychological adjustment, little attention has been dedicated to these variables associated with specific religious denominations. The Church of Jesus Christ of Latter-day Saints, commonly referred to as LDS, was identified by the Gallup survey Religion in America (2012) as one of the most committed religious groups in the U.S. In fact, according to Bengtson, Copen, Putney, and Silverstein (2009), their longitudinal study examining generational activity in the LDS faith (e.g., grandparent-parent-grandchild) showed that transmission of faith among LDS families and children remained remarkably stable over 40 years, more so than other religions. While LDS people worldwide are generally noted for their devout religious and spiritual living, more research is needed about personality traits relating to being a member of the LDS Church. However, some research, 
particularly mediating and moderating effect models has been done on LDS individuals and psychological well-being (Allen \& Heppner, 2011), adjustment, perfectionism (Allen \& Wang, 2014; Allen, Wang, \& Stokes, 2015), psychotherapy (Bergin, Payne, Jenkins, \& Cornwall, 1994; Richards \& Bergin, 2005; Richards \& Bergin, 2014), and overall mental health (Barlow \& Bergin, 1998; Koltko, 1990), but research lacks specificity around their long-term characteristics (i.e., personality) as they relate to psychological adjustment among LDS individuals.

Obtaining a better understanding of the relationship of religious and spiritual living with personality traits and well-being of religious LDS individuals could strengthen the overall understanding of this specific religion. Furthermore, it can increase the knowledge base of the relationship of religiousness, personality traits, and psychological well-being in this particular religious culture. Specifically and perhaps more importantly, the findings from this study can not only add to the existing research on religiosity and spirituality in social work practice (Derezotes \& Evans, 1995; Sheridan, 2004; Stewart, Koeske, \& Koeske, 2006), but also continue to assist social work practitioners with the knowledge and tools needed to work with religiously committed LDS individuals who may need psychological assistance. It offers mental health therapists some helpful tips, guidelines, and strategies when working with this religious population.

Based on recent research regarding specific factors and relationships among highly religious LDS individuals related to psychological well-being (Allen \& Heppner, 2011), perfectionism (Allen \& Wang, 2014; Allen, Wang, \& Stokes, 2015), coping (Allen \& Heppner, 2011), and adjustment (Allen \& Wang, 2014; Allen, Wang, \& Stokes, 2015), the purpose of this study was to add to the existing research around LDS people and well-being, more specifically adding factors such as personality traits to this body of research, which can enhance the existing research on LDS communities. The aim is that these findings about personality traits can provide more information about how LDS individuals may manifest their faith through certain influential personality factors. Therefore, this study attempts to examine relationships, including mediating/moderating effects, among the personality traits represented in the Five-Factor Model (McCrae \& Costa, 1999; Streyffeler \& McNally, 1998), religious commitment, social interaction anxiety, and anger in a highly religious LDS community. The study was designed to examine the following:

(1) Relationships among religious commitment, agreeableness, openness to experience, neuroticism, extraversion, and conscientiousness in LDS members.

(2) Whether individuals scoring high on agreeableness and neuroticism correlated with their psychological well-being, specifically related to social interaction anxiety and anger. 
(3) Whether agreeableness, openness to experience, and extraversion mediate or moderate the relationship between religious commitment and social interaction anxiety as well as anger.

\section{Methods}

\section{Participants}

Approval of the IRB review committee at the host institution was obtained. Following this approval, 110 participants were recruited ( 72 females, 38 males; mean age 22.1; 89\% response rate). Fourteen participants who were not members of the LDS Church were excluded from the study. Participants were students at a liberal arts university in a southwestern region of the U.S. All participants are LDS, and $93 \%$ reported as White. The other $7 \%$ of the sample were Asian American $(\mathrm{N}=2)$, Latino/as $(\mathrm{N}=1)$, and Polynesian American $(\mathrm{N}=1)$, and 3 reported multiracial. Participants were recruited through fliers and announcements by research assistants visiting introductory psychology courses at the university. The participants were given instructions through the SONA system in the psychology department on how to complete the study online through the survey program Qualtrics at their choice of setting. Those who accepted the invitation to participate in the study were given a 1-hour course credit for participating.

\section{Instruments}

Each participant completed the following measures: the Religious Commitment Inventory-10 (RCI-10; Worthington et al., 2003), the Big Five Inventory-44 (BFI-44; Benet-Martinez \& John, 1998), the Social Interaction Anxiety Scale (SIAS; Carleton et al., 2009), and the Clinical Anger Scale (CAS; Snell, Gum, Shuck, Mosley, \& Kite, 1995).

Religious Commitment Inventory-10 (RCI-10; Worthington et al., 2003). Worthington (1988) described religious commitment as the degree to which individuals adhere to their religious values, beliefs, and practices. The RCI-10 assesses religious commitment via a 10-item scale with two factors: intrapersonal (cognitive focus) and interpersonal (behavior focus) religious commitment. Intrapersonal items focus on individual states or actions: "It is important to me to spend periods of time in private religious thought and reflection." Interpersonal items focus on interactions or relationships: "I enjoy working in the activities of my religious organization." Participants rated each item on a five-point Likert-type scale: $1=$ not at all true of me, 2 = somewhat true of me, 3 = moderately true of me, $4=$ mostly true of me, $5=$ totally true of me. Intrapersonal religious commitment was significantly correlated with interpersonal religious commitment ( $r=.72$; Worthington et al., 2003). The alpha coefficient for the RCI-10 was .95 (Allen \& Heppner, 2011), and the test-retest 
reliability over a 5-month period was .91 (Worthington et al., 2003). For this current study, the alpha coefficient was .95 .

The Big Five Inventory-44 (BFI-44; Benet-Martinez \& John, 1998). The BFI-44 is a 44-item measure of neuroticism, extraversion, agreeableness, conscientiousness, and openness to experience. Each subscale consists of 8 to 10 items, which consist of short phrases rated on a Likert-type scale ( $1=$ Disagree Strongly, $2=$ Disagree a little, 3 = Neither Agree nor Disagree, $4=$ Agree a little, $5=$ Agree Strongly) according to how descriptive the phrases are of the respondent. McCrae \& John, (1992) estimated internal consistencies for the subscales ranging from .75 to .88 for self- and peer reports. The subscales were further validated by peer-peer and peer-self correlations that ranged from .21 for agreeableness to .63 for extraversion. For this current study, the Cronbach alpha coefficients for each personality factor were good: extraversion .90, agreeableness .74, conscientiousness .78 , neuroticism .82 , and openness .77 .

Social Interaction Anxiety Scale (SIAS; Carleton et al., 2009). The SIAS is a 19item self-report scale designed to measure fear in social interaction situations, such as individual or group conversations. Each item is rated on a five-point Likert-type scale ranging from 0 (not at all characteristic or true of me) to 4 (extremely characteristic or true of $m e$ ). The SIAS has high internal consistency, test-retest reliability, and validity. The internal consistency was high for the undergraduate sample $(\alpha=.93)$. The average inter-item correlation for the undergraduate sample was .43. For this current study, the alpha coefficient was .84 .

Clinical Anger Scale (CAS; Snell et al., 1995). The CAS is 21-item instrument that measures the psychological symptoms presumed to have relevance for understanding and treating clinical anger. The symptoms of anger measured by the CAS involve anger now, anger about the future, anger about things, angry hostile feelings, annoying others, angry about self, angry misery, wanting to hurt others, shouting at people, irritated now, social interference, decision interference, alienating others, work interference, sleep interference, fatigue, appetite interference, health interference, thinking interference, and sexual interference. Participants are asked to read each of the 21 groups of statements and select the single statement that best describes how they feel (e.g., item 1: A = I do not feel angry, $\mathrm{B}=\mathrm{I}$ feel angry, $\mathrm{C}=\mathrm{I}$ am angry most of the time now, and $\mathrm{D}=\mathrm{I}$ am so angry all the time that I can't stand it). The four statements in each cluster vary in symptom intensity, with more intense clinical anger associated with statement D. Each cluster of statements is scored on a 4-point Likert scale, with $A=0, B=1$, $\mathrm{C}=2$, and $\mathrm{D}=3$. Cronbach alpha coefficients yielded .94 (males and females together), .95 (males only), and .92 (females only). For this current study, the alpha coefficient was .83 for both males and females. 


\section{Results}

Preliminary analyses using descriptive statistics confirmed the normality of the data distributions, range of scores, and the absence of outliers. The authors sought to better understand this sample of LDS individuals, their commitment to their faith, and common personality traits by examining mean levels on these variables. Means on two of the scales, Religious Commitment (RCI) and Agreeableness (AGR), were high (RCI: $M=4.0$; AGR: $M=4.0$ ). A $t$-test was conducted to examine differences between the RCI mean for this sample and the mean reported on the initial development of the RCI-10 (Worthington et al., 2003; $M=3.4$ ). The result was statistically different between the RCI mean for this sample and the sample mean from which this instrument was normed $(t=6.81, p<.001)$. The Conscientious (CON) scale yielded a high score as well $(M=3.8)$. See Table 1 .

Table 2 summarizes the bivariate correlations among study variables. There were a number of significant correlations worth mentioning here to better understand specific associations of variables with this sample of LDS people. Related to Extraversion (EXT), there were 2 variables that were inversely correlated with EXT: Neuroticism (NEU: $r=-.40, p<.01$ ) and Social Interaction Anxiety (SIAS: $r=-.75 . p<.01$ ). In this sample, the personality trait of Extraversion was found to serve as a buffering effect

Table 1. Means and standard deviations of the study variables.

\begin{tabular}{ccccc}
\hline Measure & $M$ & $S D$ & Skewness & Kurtosis \\
\hline BFI-44 & & & & \\
EXT & 3.40 & .88 & -.21 & -.55 \\
AGR & 4.00 & .53 & -.23 & -.49 \\
CON & 3.85 & .60 & -.13 & -.78 \\
NEU & 2.70 & .75 & .07 & -.20 \\
OPN & 3.60 & .61 & -.37 & 1.01 \\
RCI & 4.04 & .98 & -1.3 & .66 \\
INTR & 4.10 & .98 & -1.3 & .95 \\
INTE & 4.00 & 1.0 & -1.2 & .49 \\
SIAS & 2.15 & .73 & .87 & .54 \\
CAS & 1.12 & .19 & 1.43 & 1.52 \\
\hline
\end{tabular}

Table 2. Correlations of study variables.

\begin{tabular}{lcccccccccc}
\hline Variable & 1 & 2 & 3 & 4 & 5 & 6 & 7 & 8 & 9 & 10 \\
\hline 1. EXT & 1 & & & & & & & & & \\
2. AGR & .18 & 1 & & & & & & & & \\
3. CON & -.04 & .05 & 1 & & & & & & & \\
4. NEU & $-.39^{* *}$ & -.18 & -.01 & 1 & & & & & & \\
5. OPN & $.37^{* *}$ & .18 & -.02 & .37 & 1 & & & & & \\
6. RCI & .10 & $.28^{* *}$ & $.26^{* *}$ & $-.24^{*}$ & -.00 & 1 & & & & \\
7. RCI-INTRA & .06 & $.29^{* *}$ & $.27^{* *}$ & $-.24^{*}$ & -.01 & $.98^{* *}$ & 1 & & & \\
8. RCI-INTER & .14 & $.25^{* *}$ & $.21^{*}$ & $-.27^{* *}$ & .01 & $.95^{* *}$ & $.87^{* *}$ & 1 & & \\
9. SIAS & $-.75^{* *}$ & $-.20^{*}$ & -.07 & -.30 & $-.34^{* *}$ & $-.22^{*}$ & -.18 & $-.27^{* *}$ & 1 & \\
10. CIAS & $-.21^{*}$ & $-.29^{* *}$ & .05 & .21 & -.12 & $-.26^{* *}$ & $-.28^{* *}$ & $-.21^{*}$ & $.40^{* *}$ & 1 \\
\hline
\end{tabular}


against potential anxiety-provoking situations. Regarding specific areas of interest in this sample, Intrapersonal Religious Commitment (RCI-INTRA) was found to be positively associated with Conscientiousness (CON; $r=.27$, $p<.01$ ), which could be related to beliefs around others-centeredness rather than self-centeredness. RCI also revealed positive correlations with Agreeableness (AGR: $r=.28, p<.01$ ), while showing an inverse correlation with Neuroticism (NEU: $r=-.21, p<.05$ ), Social Interaction Anxiety (SIAS: $r=-.22, p<.05$ ), and Anger (CAS: $r=-.26, p<.01$ ). Religiousness for this sample was negatively correlated with psychological struggles, particularly, neurotic and anxious as well as impulsive. The Agreeableness trait among these LDS individuals was also found to be inversely correlated with Social Anxiety Interaction $(r=-.20, p<.05)$ and Anger $(r=-.29, p<.01)$. However, the opposite was found related to Neuroticism and Social Anxiety Interaction and Anger. It appears that NEU was positively associated with both SIAS and CAS $(r=.59, \mathrm{p}<.01 ; r=.43, p<.01)$, indicating that when these individuals scored high on the neurotic trait, the more likely they were to show increased social interaction anxiety and anger.

\section{Indirect effects}

Recently, research has been conducted regarding similar mediation/moderation analyses on agreeableness, openness to experience, and extraversion, which have provided important information related to openness to experience and extraversion as moderators for health behavior and psychological well-being (Carlo, Okun, Knight, \& de Guzman, 2005; Korotkov, 2008). However, limited information still exists regarding mediation effects related to these constructs among religious individuals and psychological well-being. Given the findings from these studies as well as the limited current knowledge of these variables with a religious sample, the authors sought to analyze these constructs through mediation analyses.

The following correlations were observed related to the mediation analyses (Baron \& Kenny, 1986; Frazier, Tix, \& Barron, 2004; Tix \& Frazier, 2005). Based on recommendations by Frazier et al. (2004) and Tix and Frazier (2005), in order to test for evidence that a variable mediates the relationship between a predictor variable and an outcome variable, four conditions need to be met. First, there must be a significant relationship between a predictor variable (RCI) and a criterion variable (SIAS and CAS). This condition was met: RCI was inversely correlated with SIAS $(r=-.22$, $p<.01)$ and CAS $(r=-.26, p<.01)$. Second, there must be a significant relationship between predictor (RCI) and a proposed mediator variable (AGR). This condition was also met: RCI was positively correlated with AGR $(r=.28, p=.01)$. Third, there must be a significant relationship between the mediator variable (AGR) and criterion variable (SIAS and 
Table 3. Indirect effects of study variables.

\begin{tabular}{lccc}
\hline Variable & $\mathrm{R}^{2}$ Change & $B$ & $p$ value \\
\hline Mediation & & & \\
RCl predictor & & & \\
CAS criterion & .103 & -.21 & $.015^{*}$ \\
AGR mediator & & & \\
Moderation & & & \\
RCI predictor & & \\
EXT moderator & -.70 & \\
SIAS criterion & & \\
Step 1 & .14 & $.028^{*}$ \\
RCI & & \\
EXT & & \\
Step 2 & & \\
RCI X EXT & &
\end{tabular}

CAS). This condition was met: AGR was inversely correlated with SIAS ( $r=$ $.20, p=.01)$ and CAS $(r=-.29, p=.01)$. Fourth, using a regression analysis, the strength of the relationship between the predictor (RCI) and the outcome variable (SIAS) decreases significantly when the mediator variable $(A G R)$ is entered in the regression model. In this analysis, RCI was entered as a predictor (Step 1) and AGR as a mediator variable (Step 2) with SIAS and CAS (2 separate analyses) as the criterion variables.

As revealed in Table 3, results showed that the relationship between RCI and SIAS did not significantly decrease when AGR was entered into the model; thus there was no mediating effect of agreeableness between religious commitment and social interaction anxiety $(B=-.15, p=.120)$. However, there was an indirect mediating effect of agreeableness between religious commitment and anger $(B=-$ $.21, p=.015)$. It was also conceptualized that instead of the personality trait of agreeableness explaining or accounting for the negative relationship between religious commitment and social interaction anxiety, perhaps AGR could affect the direction, buffer, and/or strength of the relationship between this predictor and criterion. Therefore, a moderation analysis was performed entering AGR as a moderator variable. Results also showed no significance for AGR moderating the relationship between RCI and SIAS $\left(\mathrm{R}^{2}\right.$ adj $\left.=.061, F[1,109]=3.35, p=.182\right)$. Furthermore, a moderation analysis was performed with CAS as the criterion variable in this same relationship and again AGR was not an indirect moderating variable $\left(\mathrm{R}_{\text {adj }}^{2}=.101, F[1,109]=5.09, p=.392\right)$. However, in addition, authors sought to examine if other personality traits, such as Extraversion and Openness to Experience, would moderate or buffer the relationship between RCI and SIAS. The results showed a moderation effect of Extraversion $\left(\mathrm{R}^{2}\right.$ adj $=.589, F[1,109]=52.21$, $p=.028)$, but not for Openness to Experience $\left(\mathrm{R}_{a d j}^{2}=.149, F[1,109]=7.37\right.$, $p=.428)$. 


\section{Discussion}

The findings from this study could add and extend to the already existing information among LDS individuals and psychological processes (Allen \& Heppner, 2011; Allen \& Wang, 2014; Barlow \& Bergin, 1998; Bergin et al., 1994; Koltko, 1990; Richards \& Bergin, 2005; Richards \& Bergin, 2014). Understanding the LDS belief system, particularly as it relates to psychological well-being, is not only important for those who may be curious or may not be knowledgeable about this religious community (Allen \& Wang, 2014), but also for social work practitioners, specifically, who may work with religious LDS clients (Richards \& Bergin, 2014). These findings have implications for clinical practice and provide knowledge and possible intervention strategies for social work providers when working with this group. The elevated mean on religious commitment for this sample may be a typical characteristic across a variety of LDS individuals based on previous findings (Allen \& Heppner, 2011; Allen \& Wang, 2014). However, the elevated means on agreeableness and conscientiousness as personality traits could lend additional knowledge about social interactive patterns and dedicated religiousness of LDS individuals.

For this sample of LDS individuals, it was also apparent that there were specific factors that buffered the negative effects of social interaction anxiety, neurotic tendencies, and anger; namely religiousness, extraversion, and agreeableness. One possible explanation of these associations could be that being agreeable (i.e., being kind and understanding, "turning the other cheek") rather than confrontational or angry towards something or someone, particularly when disagreements occur in a social interaction, could be a valued religious attribute and personal characteristic among LDS people. Likewise, resorting to being extraverted (and agreeable) could possibly also alleviate potential awkwardness around a conflict or difference of opinion and mitigate the tendency to be socially anxious.

Although agreeableness seemed to be an effective trait related to decreased distress, it did not appear to be as strong a buffer as other variables, specifically religious commitment. For this highly religious LDS sample and based on the mediation and moderation analyses, agreeableness was not a significant personality trait that explained or contributed to the decreased social interaction anxiety. Instead, we found that being religiously committed, independently, did explain the decreased social interaction anxiety. The same was found for the openness to experience trait. This finding of strong religious commitment was also observed in other studies with LDS individuals (i.e., Allen \& Heppner, 2011; Allen \& Wang, 2014). In contrast, agreeableness did explain the relationship between religious commitment and anger. This could perhaps imply that in the face of more intense emotional responses such as anger, rather than rely on their religious 
commitment, this sample of LDS individuals may activate and utilize their agreeableness trait to de-escalate potentially-heated disagreements. Extraversion was also found to strengthen or add to the relationship between religious commitment and social interaction anxiety, implying that being extraverted (beyond religious commitment) could decrease the anxiety in social interactions.

In addition, based on the findings in this sample, not only do interpersonal religiously committed LDS individuals tend to show lower levels of social interaction anxiety, but also the tendency to be thoughtful and serviceoriented (conscientiousness) towards others as indicated in this sample with a significant positive correlation with both intra- and interpersonal religious commitment. This characteristic of conscientiousness could possibly be an aspect that this LDS sample seeks to adopt into their everyday lives. However, similar to being agreeable, a tendency to be overly thoughtful towards others and not towards the welfare of the self could be problematic. This may present some issues in counseling as some LDS persons may feel guilty or disappointed if they are not able to meet the expectations (Allen \& Wang, 2014) of serving others as they would like, thereby forgetting and negating their own needs and assistance for mental health. Social workers should recognize this positive others-centered attribute when working with highly religious LDS clients, while at the same time exploring alternative meanings around the importance of serving others and serving one's own needs in a more balanced way.

Lastly, in contrast, although there may be some aspects that could delay a positive therapeutic outcome in counseling with some LDS individuals, it is also important to note that perhaps building on positive psychological attributes such as their religiousness associated with their decreased distress, well-being aspects such as conscientiousness, and extraversion could create a foundation and safe place for a psychotherapeutic process to commence when working with LDS clients. Understanding these key components of LDS people could help initiate and enhance a psychotherapeutic relationship as well as a possible positive therapeutic outcome.

\section{Implications for social work providers}

Findings from this study provide several practical and clinical implications for social work providers as considerations when working with some highly religious LDS individuals in counseling. First, it would be culturally sensitive and appropriate if social work providers are aware of the heightened religious dedication of many LDS individuals, and that their strong spirituality offers a buffering effect against psychological difficulties. If social work service providers are aware of this and can incorporate this coping strategy of religiousness, psychotherapeutic outcome could more likely be positive. Second, when working with these individuals 
around religious issues, generally speaking, it is critical to be aware that certain personality traits also play a role in their psychological well-being. Although the religious commitment of LDS individuals could lead to positive mental health (Allen \& Heppner, 2011; Allen \& Wang, 2014), personality traits, such as agreeableness, may not always be a psychological healthy trait. While agreeableness, for this sample, seems to alleviate potential anger-specific situations, this attribute may also delay the positive therapeutic outcome. For instance, overly agreeable individuals, particularly in this sample, could also struggle with finding a safe place to disagree and a way to express their inner thoughts and feelings (including frustrations and anger) even when others may disagree. This could be the case while they are in session with a therapist, as well as during their interpersonal interactions with others outside of counseling. Being internally silent while outwardly showing agreement and not being able to express true beliefs could lead to greater internal distress. It is essential for social work service providers to acknowledge in session that while being agreeable could allay some potentially angerdriven situations, it may also be likewise important to illustrate what possible emotional consequences could arise among some LDS individuals if being overly agreeable is a tendency. In addition, perhaps exploring with LDS clients the conceptual and practical differences between being religiously committed and being passive and submissive (agreeableness) could offer these clients additional insight into what it means to live a religiously committed life. Being religious may not mean always being agreeable (while internally conflicted) for the purpose of avoiding contention or disagreement, particularly when one's emotional wellbeing is at risk.

Another implication for clinical practice is the attribute of conscientiousness, which is an aspect that this LDS sample strives to live. The tendency to be overly thoughtful towards others and for self could be an issue and social work clinicians should address this in session if this is connected to their distress. Social work providers may want to recognize this positive otherscentered attribute when working with highly religious LDS clients. Lastly, social work providers could utilize LDS religiosity and the attribute of conscientiousness and extraversion to create a psychotherapeutic process.

\section{Limitations}

Regarding limitations to this study, one worth mentioning is the age range of adults. The fact that the age mean was in the low 20's as well as the majority of the sample is White and American does not allow this study to infer generalizability across other age groups and races of LDS members. Factors in this age group such as life stage development and identity formulation could have influenced or overinflated the results in a direction towards agreeableness and extraversion that would otherwise not be found in other older age groups. Also, a large portion of the LDS membership is non-White and international, which this sample lacks 
relating to representation of all LDS members in the world. Future studies may include samples of different age groups and through multiple and different sources, such as LDS samples from the community (and not just one source; e.g. university setting), as well as other regions of the U.S. and internationally, as personality traits like agreeableness can be different among other faithful LDS individuals. In addition, future studies may also extend the literature by studying religious commitment, personality traits, and psychological adjustment with other religious groups in the U.S. as well as other countries. It would also be important to examine possible differences between people of mainstream and minority religious faiths as well as those with different types of doctrines (e.g., strict versus lenient, conservative versus liberal).

Another limitation is that this study was also based on self-report, which introduces the possibility of presenting oneself in a favorable manner regarding religiousness and personality. Future studies may want to consider controlling for social desirability. Finally, due to the volunteer nature of the recruitment process, those that participated might have possibly been more altruistic, compliant, and committed to their faith. Although these are limitations, the results still indicate a significant phenomenon related to how LDS members may utilize specific religious and personality characteristics to buffer psychological struggles.

\section{Conclusion}

There remains a lack of research regarding people of LDS and other religious faiths. This study will hopefully stimulate interest of other social work educators, scholars, and researchers to advance this field of research forward. The results have assisted the understanding and knowledge base of LDS living, their personality traits, and their overall well-being. In general, it offers a broader and clearer conception of members of the Church of Jesus Christ of Latter-day Saints who perhaps are having similar psychological experiences in the mainstream American culture. One of the main objectives of this study was to answer many questions that scientists and practitioners may have about this population in order to better serve them, but more importantly, the study should foster more understanding of the psychological well-being of some LDS individuals. Findings from this study may also have implications for individuals from other religious groups in the U.S. as well as other countries, which could be a next step in advancing the knowledge base. In sum, there are still many unanswered questions and much research yet to do for LDS and other religious populations.

\section{Disclosure statement}

No potential conflict of interest was reported by the authors. 


\section{References}

Allen, G. E. K., \& Heppner, P. P. (2011). Religiosity, coping, and psychological well-being among Latter-day Saint polynesians in the US. Asian American Journal of Psychology, 2(1), 13-24.

Allen, G. E. K., \& Wang, K. (2014). Examining aspects of religiosity, perfectionism, scrupulosity, and well being among LDS individuals. Psychology of Religion and Spirituality, 6(3), 257.

Allen, G. E. K., Wang, K., \& Stokes, H. (2015). Examining legalism, scrupulosity, family perfectionism, and psychological adjustment among LDS individuals. Mental Health, Religion \& Culture, 18(4), 246-258.

Allport, G. W., \& Ross, J. M. (1967). Personal religious orientation and prejudice. Journal of Personality and Social Psychology, 5(4), 432-443. doi:10.1037/h0021212

Atkinson, M., \& Violato, C. (1994). Neuroticism and coping with anger: The trans-situational consistency of coping responses. Personality and Individual Differences, 17(6), 769-782. doi:10.1016/0191-8869(94)90046-9

Barlow, S. H., \& Bergin, A. E. (1998). Religion and mental health from the Mormon perspective. In H. Koenig (Ed.), Handbook of religion and mental health (pp. 225-243). New York, NY: Academic Press. doi:10.1016/B978-012417645-4/50082-1

Baron, R. M., \& Kenny, D. A. (1986). The moderator-mediator variable distinction in social psychological research: Conceptual, strategic, and statistical considerations. Journal of Personality and Social Psychology, 51, 1173-1182. doi:10.1037/0022-3514.51.6.1173

Benet-Martinez, V., \& John, O. P. (1998). 'Los Cinco Grandes' across cultures and ethnic groups: Multitrait-multimethod analyses of the Big Five in Spanish and English. Journal of Personality and Social Psychology, 75, 729-750. doi:10.1037/0022-3514.75.3.729

Bengtson, V. L., Copen, C. E., Putney, N. M., \& Silverstein, M. (2009). A longitudinal study of the intergenerational transmission of religion. International Sociology, 24(3), 325-345. doi:10.1177/0268580909102911

Berenbaum, H., \& Williams, M. (1995). Personality and emotional reactivity. Journal of Research in Personality, 29(1), 24-34. doi:10.1006/jrpe.1995.1002

Bergin, A. E., Payne, I. R., Jenkins, P., \& Cornwall, M. (1994). Religion and mental health: Mormons and other groups. In M. Cornwall, T. Heaton, \& L. Young (Eds.), Contemporary Mormonism: Social science perspectives (pp. 138-158). Chicago: University of Illinois Press.

Carleton, R. N., Collimore, K. C., Asmundson, G. J., McCabe, R. E., Rowa, K., \& Antony, M. M. (2009). Refining and validating the social interaction anxiety scale and the social phobia scale. Depression and Anxiety, 26(2), E71-E81. doi:10.1002/da.20480

Carlo, G., Okun, M. A., Knight, G. P., \& de Guzman, M. R. T. (2005). The interplay of traits and motives on volunteering: Agreeableness, extraversion and prosocial value motivation. Personality and Individual Differences, 38(6), 1293-1305. doi:10.1016/j.paid.2004.08.012

Cervantes, J. M., \& Parham, T. A. (2005). Toward a meaningful spirituality for people of color: Lessons for the counseling practitioner. Cultural Diversity \& Ethnic Minority Psychology, 11(1), 69-81. doi:10.1037/1099-9809.11.1.69

Cianocchi, J. W., Piedmont, R. L., \& Williams, J. E. (2003). Love thy neighbor: Spirituality and personality as predictors of prosocial behavior in men and women. Research in the Social Scientific Study of Religion, 14, 61.

Costa, P. T., Jr, \& McCrae, R. R. (1990). Personality disorders and the five-factor model of personality. Journal of Personality Disorders, 4(4), 362-371. doi:10.1521/ pedi.1990.4.4.362 
Derezotes, D. S., \& Evans, K. E. (1995). Spirituality and religiosity in practice: In-depth interviews of social work practitioners. Social Thought, 18(1), 39-56. doi:10.1080/ 15426432.1995.9960214

Elkins, D. (1977). The effect of prayer on tension reduction (Unpublished doctoral dissertation). Nashville, TN: George Peabody College for Teachers.

Elkins, D., Anchor, K. N., \& Sandler, H. M. (1979). Relaxation training and prayer behavior as tension reduction techniques. Behavioral Engineering, 5(3), 81-87.

Finney, J. R., \& Malony, H. N. (1985). Empirical studies of Christian prayer: A review of the literature. Journal of Psychology and Theology, 13(2), 104-115. doi:10.1177/ 009164718501300203

Francis, L. J. (2005). Prayer, personality and purpose in life among churchgoing and nonchurchgoing adolescents. Religion, education and adolescence: International empirical perspectives (pp. 15-38).

Francis, L. J., \& Ross, C. F. J. (2000). Personality type and quest orientation of religiosity. Journal of Psychological Type, 55, 22-25.

Frazier, P. A., Tix, A. P., \& Barron, K. E. (2004). Testing moderator and mediator effects in counseling psychology research. Journal of Counseling Psychology, 51(1), 115. doi:10.1037/ 0022-0167.51.1.115

Gallup Survey on Religion in America (2012). Religion in America. Retrieved from https:// news.gallup.com/poll/1690/religion.aspx

Goldberg, L. R., \& Saucier, G. (1998). What is beyond the Big Five?. Journal of Personality, 66 (4), 495-524. doi:10.1111/1467-6494.00022

Harmon-Jones, E., \& Sigelman, J. (2001). State anger and prefrontal brain activity: Evidence that insult-related relative left-prefrontal activation is associated with experienced anger and aggression. Journal of Personality and Social Psychology, 80(5), 797-803. doi:10.1037/ 0022-3514.80.5.797

Hertsgaard, D., \& Light, H. (1984). Anxiety, depression, and hostility in rural women. Psychological Reports, 55(2), 673-674.

Hong, S. M., \& Withers, C. M. (1982). Trait anger, locus of control, religiosity, and authoritarianism as related to trait anxiety. Psychological Reports, 51(3), 941-942. doi:10.2466/pr0.1982.51.3.941

Jansen, K. L., Motley, R., \& Hovey, J. (2010). Anxiety, depression and students' religiosity. Mental Health, Religion \& Culture, 13(3), 267-271. doi:http://dx/doi.org/10.1080/ 13674670903352837

Kay, A. C., Gaucher, D., McGregor, I., \& Nash, K. (2010). Religious belief as compensatory control. Personality and Social Psychology Review, 14(1), 37-48. doi:10.1177/ 1088868309353750

Koenig, H. G., Hays, J. C., George, L. K., Blazer, D. G., Larson, D. B., \& Landerman, L. R. (1997). Modeling the cross-sectional relationships between religion, physical health, social support, and depressive symptoms. The American Journal of Geriatric Psychiatry, 5, 131-144. doi:10.1097/00019442-199721520-00006

Koltko, M. E. (1990). How religious beliefs affect psychotherapy: The example of Mormonism. Psychotherapy: Theory, Research, Practice, Training, 27(1), 132. doi:10.1037/ 0033-3204.27.1.132

Korotkov, D. (2008). Does personality moderate the relationship between stress and health behavior? Expanding the nomological network of the five-factor model. Journal of Research in Personality, 42(6), 1418-1426. doi:10.1016/j.jrp.2008.06.003

Kosek, R. B. (1999). Adaptation of the Big Five as a hermeneutic instrument for religious construct. Personality and Individual Differences, 27, 229-237. doi:10.1016/S0191-8869(98)00235-9 
Maton, K. I. (1989). The stress-buffering role of spiritual support: Cross-sectional and prospective investigations. Journal for the Scientific Study of Religion, 28(3), 310-323. doi:10.2307/1386742

McCrae, R. R., \& Costa, P. T., Jr. (1999). A five-factor theory of personality. Handbook of Personality: Theory and Research, 2, 139-153.

McCrae, R. R., \& John, O. P. (1992). An introduction to the five\# factor model and its applications. Journal of Personality, 60(2), 175-215.

Merrill, R., Read, C., \& LeCheminant, A. (2009). The influence of religiosity on positive and negative outcomes associated with stress among college students. Mental Health, Religion \& Culture, 12(5), 501-511. doi:10.1080/13674670902774106

Paloma, M. M., \& Pendelton, B. F. (1991). The effects of prayer and prayer experiences on measures of general well-being. Journal of Psychology and Theology, 19, 71-83. doi:10.1177/ 009164719101900107

Piedmont, R. L. (1999). Does spirituality represent the sixth factor of personality? Spiritual transcendence and the five-factor model. Journal of Personality, 67(6), 985-1013. doi:10.1111/1467-6494.00080

Piedmont, R. L., \& Wilkins, T. A. (2005). The role of personality in understanding religious and spiritual constructs. Handbook of the Psychology of Religion and Spirituality, 1, 253-273.

Piedmont, R. L., Ciarrochi, J. W., Dy-Liacco, G. S., \& Williams, J. E. (2009). The empirical and conceptual value of the spiritual transcendence and religious involvement scales for personality research. Psychology of Religion and Spirituality, 1(3), 162. doi:10.1037/ a0014883

Richards, P. S., \& Bergin, A. E. (2005). Religious and spiritual assessment. A spiritual strategy forcounseling and psychotherapy (pp. 219-249).

Richards, P. S., \& Bergin, A. E. (2014). Religious diversity and psychotherapy: Conclusions, recommendations, and future directions. (2nd ed., pp. 475-487). Washington, DC: American Psychological Association.

Roccas, S., Sagiv, L., Schwartz, S. H., \& Knafo, A. (2002). The big five personality factors and personal values. Personality and Social Psychology Bulletin, 28(6), 789-801. doi:10.1177/ 0146167202289008

Saroglou, V. (2002). Religion and the five factors of personality: A meta-analytic review. Personality and Individual Differences, 32, 15-25. doi:10.1016/S0191-8869(00)00233-6

Schneider, S., \& Kastenbaum, R. (1993). Patterns and meanings of prayer in hospice caregivers: An exploratory study. Death Studies, 17, 471-485. doi:10.1080/07481189308252633

Sheridan, M. J. (2004). Predicting the use of spiritually-derived interventions in social work practice: A survey of practitioners. Journal of Religion \& Spirituality in Social Work: Social Thought, 23(4), 5-25. doi:10.1300/J377v23n04_02

Snell, W. E., Gum, S., Shuck, R. L., Mosley, J. A., \& Kite, T. L. (1995). The Clinical Anger Scale: Preliminary reliability and validity. Journal of Clinical Psychology, 51(2), 215-226. doi:10.1002/1097-4679(199503)51:2\%3C215::AID-JCLP2270510211\%3E3.0CO;2-Z

Stewart, C., Koeske, G. F., \& Koeske, R. D. (2006). Personal religiosity and spirituality associated with social work practitioners' use of religious-based intervention practices. Journal of Religion \& Spirituality in Social Work: Social Thought, 25(1), 69-85. doi:10.1300/J377v25n01_05

Storch, E. A., Storch, J. B., \& Adams, B. G. (2002). Intrinsic religiosity and social anxiety of intercollegiate athletes. Psychological Reports, 91(1), 186. doi:10.2466/pr0.2002.91.1.186

Streyffeler, L. L., \& McNally, R. J. (1998). Fundamentalists and liberals: Personality characteristics of Protestant Christians. Personality and Individual Differences, 24(4), 579-580. doi:10.1016/S0191-8869(97)00189-X 
Tix, A. P., \& Frazier, P. A. (2005). Mediation and moderation of the relationship between intrinsic religiousness and mental health. Personality \& Social Psychology Bulletin, 31(3), 295-306. doi:10.1177/0146167204271592

Walsh, F. (1999). Religion and spirituality: Well-springs for healing and resilience. In F. Walsh (Ed.), Spiritual resources in family therapy (pp. 3-27). New York, NY: Guilford Press.

Watson, D., \& Clark, L. A. (1984). Negative affectivity: The disposition to experience aversive emotional states. Psychological Bulletin, 96(3), 465. doi:10.1037/0033-2909.96.3.465

Wink, P., Ciciolla, L., Dillon, M., \& Tracy, A. (2007). Religiousness, spiritual seeking, and personality: Findings from a longitudinal study. Journal of Personality, 75(5), 1051-1070. doi:10.1111/j.1467-6494.2007.00466.x

Worthington, E. L. (1988). Understanding the values of religious clients: A model and its application to counseling. Journal of Counseling Psychology, 35(2), 166.

Worthington, E. L., Wade, N. G., Hight, T. L., Berry, J. W., Schmitt, M. M., Ripley, J. S., ... O'Connor, L. (2003). The religious commitment inventory-10: Development, refinement, and validation of a brief scale for research and counseling. Journal of Counseling Psychology, 50(1), 84-96. doi:10.1037/0022-0167.50.1.84

Yeh, C. J., Arora, A. K., \& Wu, K. A. (2006). A new theoretical model of collectivistic coping. In P. T. P. Wong \& L. C. J. Wong (Eds.), Handbook of multicultural perspectives on stress and coping (pp. 56-60). New York, NY: Springer Science Business Media. doi:10.1007/ 0-387-26238-5_3

Yeh, C. J., Inman, A. C., Kim, A. B., \& Okubo, Y. (2006). Asian American families' collectivistic coping strategies in response to 9/11. Cultural Diversity \& Ethnic Minority Psychology, 12(1), 134-148. doi:10.1037/1099-9809.12.1.134 